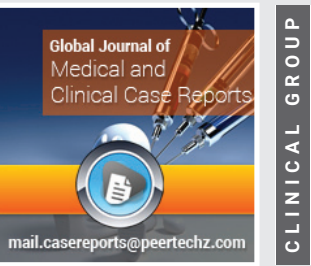

Letter to Editor

\section{Spontaneous pneumothorax associated with COVID-19}

\author{
S Alaoui Rachidi ${ }^{1,2}$ and Y Motiaa ${ }^{1,3 *}$ \\ ${ }^{1}$ Faculty of Medicine and Pharmacy of Tangier, Abdelmalek Essaadi University, Tangier, Morocco \\ ${ }^{2}$ Radiology Department, University Hospital in Tangier, Morocco \\ ${ }^{3}$ Anesthesia and Intensive Care Department, University Hospital in Tangier, Morocco
}

Received: 11 May, 2020

Accepted: 25 May, 2020

Published: 26 May, 2020

*Corresponding author: Dr. Youssef Motiaa, Department of Anesthesia and Intensive Care, University Hospital in Tangier, Faculty of Medicine and Pharmacy of Tangier, Abdelmalek Essaadi University, Tangier, Morocco, E-mail: youssefmotiaa@gmail.com

https://www.peertechz.com

Check for updates

\section{Dear Editor}

Primary spontaneous pneumothorax is due to Spontaneous rupture of a subpleural bulla [1], this complication occured in $1 \%$ of COVID-19 patients [2]. We present a case of COVID-19 pneumonia associated with an isolated spontaneous pneumothorax without barotrauma.

A 34 year old woman, with no significant past medical history of smoking, respiratory illnes or trauma and without family history of connective tissue disease or emphysema, was diagnosed six days before admission with coronavirus disease 2019 (COVID19) infection using the reverse transcriptasepolymerase chain reaction (RT-PCR) on nasopharyngeal swabs, the symptoms at onset of illness were cough, myalgia, fatigue and fever. Along with supportive care, the patient was started on chloroquine $500 \mathrm{mg}$ twice daily and azithromycin $500 \mathrm{mg}$ the first day then $250 \mathrm{mg}$ four times daily as recommended by the moroccan committee of experts at the Ministry of Health. Four days after her admission to hospital, the patient started complaining of a worsening shortness of breath and chest pain with no hemoptysia, desaturation or hypotension. She was alert with a Glasgow Coma scale score of 15 , her respiratory rate was $14-18$ cycles/min, her blood pressure was $130 / 80 \mathrm{mmHg}$, her heart rate was 100 beats per min and there was no obvious subcutaneous emphysema on examination. Contrast-enhanced Computed tomography (Figure 1) showed Contrast-enhanced Computed tomography showed a small pneumothorax on the right side $(\mathrm{A})$, bilateral rounded ground-glass opacities in both upper and lower lobes (B) with no bullae or evidence of pulmonary embolism. We opted for a conservative management of the pneumothorax given its small size, after 10 days of watch and wait, the patient is hospitalized with improving clinical conditions. Computed tomography is provided after the patient's discharge to check the pneumothorax.
In addition to pulmonary embolism and secondary bacterial pneumonia, a primary spontaneous pneumothorax in previously healthy patient can also complicate a SARS-COV2 pneumonia.

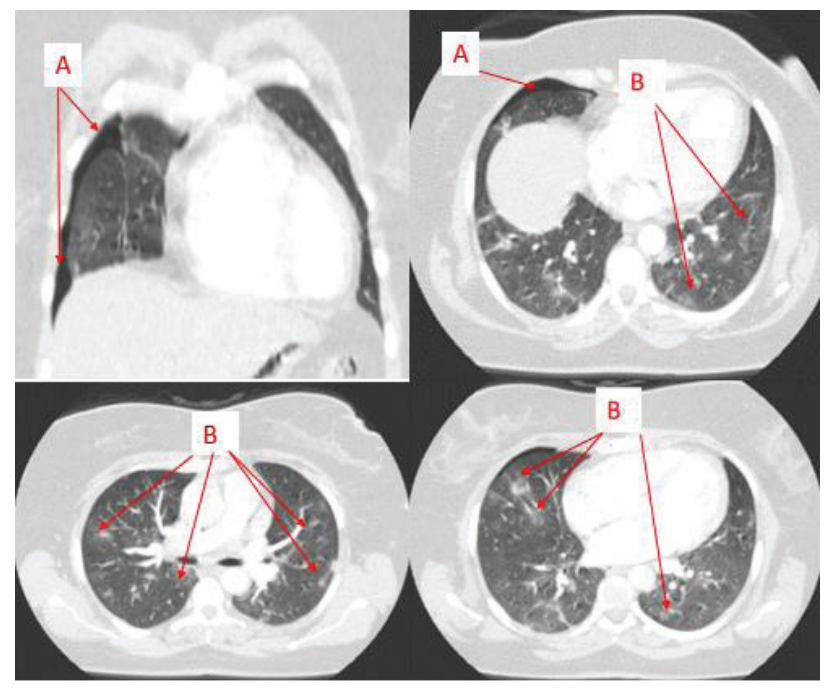

Figure 1: Contrast-enhanced computed tomography

A : small pneumothorax on the right side.

B : bilateral rounded ground-glass opacities in both upper and lower lobes.

\section{References}

1. Light RW (1993) Management of spontaneous pneumothorax. Am Rev Respir Dis 148: 245-248. Link: https://bit.ly/2X10jza

2. Chen N, Zhou M, Dong X Qu J, Gong F et al. (2020) Epidemiological and clinical characteristics of 99 cases of 2019 novel coronavirus pneumonia in Wuhan, China: a descriptive study. Lancet 395: 507-513. Link: https://bit.ly/2TyTgeY 